\title{
ORIGINAL RESEARCH \\ Joint Influence of Individual Choices, Parenting Practices, and Physician Advice on Adolescent Obesity, Nebraska, 2008
}

\author{
Hongmei Wang, PhD; Jungyoon Kim, PhD; Dejun Su, PhD; Liyan Xu, MD; \\ Li-Wu Chen, PhD; Terry T-K. Huang, PhD
}

\begin{abstract}
Suggested citation for this article: Wang H, Kim J, Su D, Xu L, Chen L, Huang TT. Joint Influence of Individual Choices, Parenting Practices, and Physician Advice on Adolescent Obesity, Nebraska, 2008. Prev Chronic Dis 2014;11:140210. DOI: http:// dx.doi.org/10.5888/pcd11.140210.
\end{abstract}

\section{PEER REVIEWED}

\section{Abstract}

\section{Introduction}

Reducing childhood obesity remains a public health priority given its high prevalence and its association with increased risk of adult obesity and chronic diseases. The objective of this study was to examine the joint influence of multiple risk factors on adolescent overweight status.

\section{Methods}

We conducted a random-digit-dialed telephone survey of adolescents aged 12 to 19 years in fall 2008 in a Midwestern city in Nebraska. On the basis of survey data for 791 youths aged 12 to 18 years, we conducted latent class analysis to group youths by the joint occurrence of dietary behavior, physical activity, parenting practices, and physician advice. We then examined the association between the groups and overweight status by using logistic regression, controlling for age, sex, race/ethnicity, and parent and family information.

\section{Results}

Youths were clustered into 3 groups. Group I (52\%) were youths with healthy dietary behavior and physical activity, less permissive parenting practices, and physician advice; Group II (30\%) were youths with moderately healthy dietary behavior and physical activity, less permissive parenting practices, and no physician advice; and Group III (18\%) were youths with unhealthy dietary behavior and physical activity, permissive parenting practices, and physician advice. Youths in Groups I and II were less likely to be overweight than youths in Group III.

\section{Conclusions}

Youths with healthier behavior and less permissive parenting practices were less likely to be overweight. Study findings highlight the need to address obesity risk factors among youths with unhealthy dietary behavior, inadequate exercise, permissive parenting practices, and some physician advice. Tailored interventions should be used to target youths with different obesity risk factors.

\section{Introduction}

The prevalence of childhood obesity and overweight has been increasing in the United States since the 1980s. This trend appears to be stabilizing but remains high $(1,2)$. Adolescent obesity has been particularly difficult to address: although the obesity rate for children aged 2 to 5 years has recently declined, a similar decline among children aged 6 years or older has not been seen (2). In 2012 about $21 \%$ of US youths aged 12 to 19 years were obese (2).

Childhood obesity appears to be a result of low energy expenditure and high energy intake (3). Childhood obesity interventions have focused on promoting child behavior changes for a more healthful diet, a higher level of physical activity, or both. A family-based approach is increasingly emphasized to control childhood obesity, because parents play a critical role in providing a home environment that fosters healthful eating and physical activity for children and adolescents, ultimately affecting their weight status $(4,5)$. Recently, attention has also been given to the role of physicians in adolescents' weight management (6). Because behavior risks are interrelated, children and adolescents who are at risk for unhealthy eating are also more likely to have less physical activity and more screen time (7). A multiple health behavior change approach for obesity prevention is needed to address multiple risk behavior domains at multiple levels $(8,9)$. 
Interest is increasing in the interconnections among multiple overweight and obesity risk factors and in tailoring interventions for different population subgroups. However, studies to date have focused on identifying the main effects of single risk factors and, to a lesser extent, of 2- or 3-way interactions. For dietary behaviors, studies showed an inconsistent relationship between fruit and vegetable consumption and child body mass index $\left(\mathrm{kg} / \mathrm{m}^{2}\right)(\mathrm{BMI})$ $(10,11)$ and a negative association between regular breakfast consumption and childhood obesity outcomes $(12,13)$. Studies of child physical activity and weight status also showed mixed results, although most studies found an inverse association of physical activity or sports team participation with overweight and obesity outcomes or a direct association of inactivity and sedentary behavior with overweight and obesity outcomes (14-17). Research using various measures of parenting practices regarding diet and physical activity yields inconsistent results for adolescents. One measure of parenting practice, letting a youth decide what to eat, was found to be associated with unhealthy eating behaviors, such as skipping breakfast (18). Although 1 study found that rules restricting sedentary time were associated with less TV watching (19), another study found that such rules were associated with undesirable behaviors and increases in children's BMI (20). An authoritative parenting style, where parents are both responsive to children's needs and controlling of children's behaviors, was associated with healthier eating, more physical activity, and lower BMI among children (21). Physician advice has a positive effect on adolescents' weight loss attempts (22), but no evidence has been reported on its association with adolescents' weight change. Some studies included both physical activity and dietary behavior indicators in their analysis but did not show a consistent pattern of how these behaviors simultaneously affect adolescent obesity outcomes (23-25). To date, studies rarely considered the combination of individual behavior risk factors with parenting practices and access to physician advice, and the patterns in which these factors congregate, possibly because of methodological restrictions and unavailable data. The objective of this study was to examine the joint influence of multiple risk factors on adolescent overweight status.

We used latent class analysis (LCA) to categorize youths aged 12 to 18 years in a Midwestern city into several mutually exclusive groups based on patterns of modifiable obesity risk factors in 4 domains: dietary behavior, physical activity, parenting practices, and physician advice. To examine the joint influence of multiple risk factors on adolescent overweight, we also conducted logistic regression to see whether each of the 4 risk-factor groups was associated with overweight status, after controlling for each youth's sociodemographic factors. The study contributes to the field in 3 ways. First, the study enhances the understanding of the unique patterns of adolescent dietary and physical activity behavior as well as parenting practices and physician involvement. Second, the study provides valuable information for stakeholders to use in prioritizing interventions and developing programs for youths with different behavior patterns. Tailored interventions for youths exposed to particular sets of risk factors use scarce health care resources more effectively. Third, this study addresses a lack of data on adolescent risk factors for obesity, especially data on parenting practices and physician advice, by providing relevant evidence to assess the importance of these factors in youths' overweight status and to inform interventions in this high-risk group.

\section{Methods}

\section{Data and sample}

In a city in Nebraska, a telephone survey was conducted in September and October 2008 to collect information on adolescents' height and weight, dietary and physical activity behavior, parenting practices, and physician advice regarding dietary behavior and physical activity. Questions measuring behavior were adapted from the Centers for Disease Control and Prevention's (CDC's) Youth Risk Behavior Survey Questionnaire (26). The dietary behavior and physical activity questions had moderate reliability scores (27). We administered a cross-sectional, random-digitdialed telephone survey to youths aged 12 to 19 years who lived with their parents or guardians. Interviewers spoke first with parents or guardians to explain the study and obtain their permission for their children to participate. The interviewer then explained the study purpose and obtained the youth's consent. If more than 1 youth aged 12 to 19 years resided in the household, 1 youth was randomly selected. Interviews were conducted in either English or Spanish. The study was approved by University of Nebraska Medical Center Institutional Review Board in 2008. We had 894 completed surveys, and a response rate of $37.5 \%$. We excluded incomplete records and youths aged 19 years because they were considered to be young adults. Our final sample was 791 participants aged 12 to 18 years.

\section{Measurements}

Participant overweight status was determined by whether the youth's BMI percentile was equal to or greater than the 85 th percentile for his or her age and sex based on the standard CDC growth chart.

\footnotetext{
The opinions expressed by authors contributing to this journal do not necessarily reflect the opinions of the U.S. Department of Health and Human Services, the Public Health Service, the Centers for Disease Control and Prevention, or the authors' affiliated institutions.
} 
Nine observed items in the following 4 domains were used for LCA to identify subgroups of youths: 1) Dietary behavior was captured by 2 variables: whether the youth a) ate breakfast every day and b) consumed at least 5 servings of fruits and vegetables on 4 or more days a week. 2) Physical activity was measured by 3 variables: a) whether the youth engaged in at least 1 hour of physical activity on 4 or more days a week, b) participated on at least 1 sports team, and c) watched television or played video games less than 2 hours a day during weekdays. 3) Parenting practices regarding eating and physical activity were measured by 2 variables: whether parents let the youth decide a) what to eat and b) how long to watch television or play video games. 4) Physician advice was measured by 2 variables: whether, during the last routine physical examination within the previous 12 months, a doctor talked with the youth about a) nutrition and healthy eating and b) exercise and physical activity.

Age was categorized into 2 groups: 12 to 14 years and 15 to 18 years. Race/ethnicity was considered a binary indicator with nonHispanic white as the reference group. Family structure was used as a binary indicator with youths not living with both parents as the reference group. The indicator for parents' education was whether either parent attended college or university.

\section{Analysis}

We used LCA to create mutually exclusive subgroups of adolescents. LCA is a statistical technique to classify subjects into smaller subgroups on the basis of their response patterns to a set of observed categorical variables (28). LCA uses maximum likelihood estimation to obtain latent class membership probabilities and item-response probabilities. An item-response probability that is close to 1 or 0 indicates greater group heterogeneity. We examined multiple models to fit different numbers of latent classes and chose the best model by using the Bayesian information criterion (BIC). A lower BIC implies a better balance between fitting the data and parsimony $(28,29)$. After we classified the participants using LCA, we examined the differences among groups and ran a weighted logistic regression to examine the relationship between group members and each youth's overweight status. SAS version 9.2 (SAS Institute, Inc) and Proc LCA version 1.2.5 (Penn State Methodology Center) were used for analysis.

\section{Results}

Forty-six percent of participants were aged 12 to 14 years, 53\% were boys, $85 \%$ were non-Hispanic white, $12 \%$ had no parent who attended college or university, and $87 \%$ lived with both parents (Table 1).
Over $61 \%$ reported eating breakfast every day, and $63 \%$ reported eating 5 or more servings of fruits and vegetables per day for 4 days or more a week. Eighty percent engaged in at least 60 minutes of physical activity for 4 days or more a week, $77 \%$ participated in at least 1 sports team, and $67 \%$ watched television or played video games for less than 2 hours a day during weekdays. Eighty percent of participants reported that their parents let them choose what to eat, and $66 \%$ reported that their parents let them decide how much time to spend watching television or playing video games. During their last routine physical examination within the previous 12 months, $57 \%$ received physician advice on nutrition and $61 \%$ received physician advice on physical activity. About 24\% were overweight, which is lower than the national average (2).

\section{Latent class analysis results}

Three unique latent classes emerged (Table 2). Group I showed healthy dietary behavior, with the highest probability of eating breakfast every day (0.76) and of having 5 servings of fruits and vegetables for 4 or more days a week (0.76). Youths in this group also engaged in the most physical activity (the probability of having 1 hour of physical activity at least 4 days a week was 0.90 , of participating on at least 1 sports team was 0.92 , and of having less than 2 hours of screen time was 0.78 ). Of the 3 groups, youths in Group I were most likely to have received physician advice during the last routine physical examination (advice on nutrition, 0.84 ; advice on physical activity, 0.86 ). Parents in this group were less permissive regarding television watching or video game playing (the probability of letting adolescents decide how much time to watch television or play video games was 0.60 ). Group I consisted of $52 \%$ of the sample.

Group II youths had unhealthier dietary behavior and less physical activity, more permissive parenting practices, and lower physician involvement than those in Group I. Adolescents in this group still showed a high probability of physical activity behavior (eg, involved in at least 1 sports team, 0.73 ), but had a moderate probability of having healthy dietary behavior (eg, eating breakfast every day, 0.55). Probabilities for permissive parenting practices were higher than in Group I (eg, letting the youth choose what to eat, 0.81 , and how much time to watch television and play video games, 0.62). A unique characteristic of Group II was that it had the lowest probabilities of receiving physician advice (advice on nutrition, 0.01 , and advice on physical activity, 0.04). This group consisted of $30 \%$ of the adolescents in the sample.

The opinions expressed by authors contributing to this journal do not necessarily reflect the opinions of the U.S. Department of Health and Human Services, the Public Health Service, the Centers for Disease Control and Prevention, or the authors' affiliated institutions. 
Group III had the unhealthiest dietary behavior and physical activity and the most permissive parenting practices. Members of this group were less likely to report healthy dietary behavior (eg, fruit and vegetable consumption, 0.45) and physical activity (eg, less screen time, 0.42). Probabilities for permissive parenting practices for this group were the highest among the 3 groups $(0.93$ and $0.86)$. Youths in this group were also more likely to receive physician advice ( 0.67 and 0.79$)$ than those in Group II. This group consisted of $18 \%$ of the youths in the sample.

Compared with youths in Group I, youths in Group III were more likely to be overweight, older, female, and from a minority race or ethnic group; were more likely to have non-college educated parents; and were less likely to live with both parents (Table 1). Youths in Group II were also older and less likely to live with both parents than those in Group I.

\section{Logistic regression results}

The logistic regression results suggest that Group I youths were less likely to be overweight than those in Group III, the reference group (odds ratio [OR], 0.44; 95\% confidence interval [CI], 0.26-0.75) (Table 3). Similarly, youths in Group II were also less likely to be overweight than those in Group III (OR, 0.35; 95\% CI $0.25-0.48)$. The comparison between these groups suggested that healthy individual behaviors and less permissive parenting practices regarding physical inactivity were conducive to healthier weight status among adolescents.

The logistic regression results suggested that boys were more likely to be overweight than girls (OR, 1.50; 95\% CI, 1.42-1. 59). Non-Hispanic white youths were less likely to be overweight than youths from minority races (OR, 0.31; 95\% CI, 0.22-0.46). Parents' education, youth's age, and youth living with both parents were not significantly associated with overweight status.

\section{Discussion}

Our results indicated that adolescents in our study were differently exposed to the 4 obesity risk factors we considered: dietary behavior, physical activity, parenting practices, and physician advice. Three latent classes emerged: youths with healthy dietary behavior and physical activity, less permissive parenting practices, and physician advice (Group I); youths with moderately healthy dietary behavior and physical activity, less permissive parenting practices, and physician advice (Group II); and youths with unhealthy dietary behavior and physical activity, permissive parenting practices, and physician advice (Group III). The group patterns identified in our analysis suggest that unhealthy behaviors are not only interrelated, as suggested in the literature (7); they also co-occur with permissive parenting practices and physician advice to youths.

The logistic regression analysis results suggested that categorizing these youths into 3 groups was meaningful in explaining youth weight status. Youths from Group III were more likely to be overweight than those from Group I and II. This finding highlights the need to make addressing obesity risk factors a priority for adolescents with unhealthy eating behaviors, inadequate exercise, more permissive parenting practices, and physician advice. Compared with youths in Group I, youths in Group III were likely to be older, female, and from a minority race; to have non-college educated parents; and less likely to live with both parents. Interventions targeting this group should be the priority for allocating limited resources to address adolescent obesity and overweight. This finding also supports the call for interventions to target multiple risk behaviors that address multiple domains of obesity risk factors (8). Multidimensional interventions in all 4 areas should be jointly implemented to improve the weight status of youths in Group III.

This study adds to the current understanding of adolescent obesity by illustrating how risk factors jointly influence the weight status of youths. Healthy individual behaviors and less permissive parenting practices together had a strong association with a better weight outcome for adolescents. Because parents in Group I and II were less permissive regarding sedentary behavior than parents in Group III, our results reinforce previous findings that some parental control over behaviors may be effective in maintaining healthy weight among youths $(18,19)$. A family-based approach that considers family background and stresses the role of parenting in shaping children's obesity-related behaviors may be most effective $(4,5)$.

Interestingly, we did not observe much difference in weight status between Group I and Group II. Although youths in both groups were physically active and received similar parenting, youths in Group II showed less healthy dietary behavior and were less likely to receive physician advice on nutrition and physical activity than those in Group I. One possible explanation for the lack of difference between these 2 groups might be the lack of specificity in some behavior indicators, such as total calorie or total sugar and fat intake (11). The results could be due to Group II having an elevated risk for obesity but having not yet gained excessive weight. If this explanation is accurate, then this group should also be targeted for future intervention to prevent obesity. Another plausible

\footnotetext{
The opinions expressed by authors contributing to this journal do not necessarily reflect the opinions of the U.S. Department of Health and Human Services, the Public Health Service, the Centers for Disease Control and Prevention, or the authors' affiliated institutions.
} 
explanation could be that a physician did not discuss nutrition or physical activity during a consultation with healthy-weight youths. Because only about half of pediatricians calculate adolescents' BMI during a routine visit (30), there is still room for physicians to play a more active role in obesity prevention.

This study has several limitations. First, given that the study sample was from a single Midwestern city and the response rate was relatively low, the results may not be readily generalizable to a larger population. Second, the cross-sectional data used do not allow us to infer causality, and the data did not include information on some obesity risk factors such as inadequate sleep and poor mental health status. Third, the parenting practices and physician advice measures used were relatively crude, and validated measures should be used in future studies. Lastly, we used self-reported BMI to measure overweight status, which may have underestimated the likelihood of overweight. However, we do not expect that these limitations are sufficiently severe to change study results on the youth groups and their relationship to overweight status.

These limitations notwithstanding, our study showed a need to simultaneously examine the complex set of factors and their patterned congregations in relation to adolescent obesity. Concrete efforts in individual, family, and primary care settings are important to shape adolescent behaviors and to help adolescents maintain a healthy weight. The physician's role may need to be expanded from a predominant focus on management of obesity-related conditions to a more active approach to obesity prevention. The 3 youth groups identified in our study and their different risks of overweight also suggest that obesity interventions will be more effective if they are customized for particular behavioral and contextual phenotypes of youth.

\section{Acknowledgments}

This project was commissioned by Live Well Omaha Kids and funded by Alegent Health.

\section{Author Information}

Corresponding Author: Hongmei Wang, PhD; Department of Health Services Research and Administration, College of Public Health, University of Nebraska Medical Center, 984350 Nebraska Medical Center, Omaha, NE 68198-4350. Telephone: 402-5599413. E-mail: hongmeiwang@unmc.edu.
Author Affiliations: Jungyoon Kim, Dejun Su, Li-Wu Chen, University of Nebraska Medical Center, Omaha, Nebraska; Liyan $\mathrm{Xu}$, Creighton University, Omaha, Nebraska; Terry T-K Huang, City University of New York School of Public Health, New York, New York. At the time this article was written, Drs. Xu and Huang were affiliated with the University of Nebraska Medical Center, Omaha, Nebraska.

\section{References}

1. Wabitsch M, Moss A, Kromeyer-Hauschild K. Unexpected plateauing of childhood obesity rates in developed countries. BMC Med 2014;12:17.

2. Ogden CL, Carroll MD, Kit BK, Flegal KM. Prevalence of childhood and adult obesity in the United States, 2011-2012. JAMA 2014;311(8):806-14.

3. Hill JO, Peters JC. Environmental contributions to the obesity epidemic. Science 1998;280(5368):1371-4.

4. Lindsay AC, Sussner KM, Kim J, Gortmaker S. The role of parents in preventing childhood obesity. Future Child 2006; 16(1):169-86.

5. Sung-Chan P, Sung YW, Zhao X, Brownson RC. Familybased models for childhood-obesity intervention: a systematic review of randomized controlled trials. Obes Rev 2013; 14(4):265-78.

6. Lumeng JC, Castle VP, Lumeng CN. The role of pediatricians in the coordinated national effort to address childhood obesity. Pediatrics 2010;126(3):574-5.

7. Driskell MM, Dyment S, Mauriello L, Castle P, Sherman K. Relationships among multiple behaviors for childhood and adolescent obesity prevention. Prev Med 2008;46(3):209-15.

8. Jackson CA, Henderson M, Frank JW, Haw SJ. An overview of prevention of multiple risk behaviour in adolescence and young adulthood. J Public Health (Oxf) 2012;34(Supp1 1):i31-40.

9. Huang TT, Drewnowski A, Kumanyika SK, Glass TA. A systems-oriented multilevel framework for addressing obesity in the 21st century. Prev Chronic Dis 2009;6(3):A82. http:// www.cdc.gov/pcd/issues/2009/jul/09_0013.htm. Accessed July 20, 2014.

10. Vernarelli JA, Mitchell DC, Hartman TJ, Rolls BJ. Dietary energy density is associated with body weight status and vegetable intake in US children. J Nutr 2011;141(12):2204-10.

11. Field AE, Gillman MW, Rosner B, Rockett HR, Colditz GA. Association between fruit and vegetable intake and change in body mass index among a large sample of children and adolescents in the United States. Int J Obes Relat Metab Disord 2003;27(7):821-6.

\footnotetext{
The opinions expressed by authors contributing to this journal do not necessarily reflect the opinions of the U.S. Department of Health and Human Services, the Public Health Service, the Centers for Disease Control and Prevention, or the authors' affiliated institutions.
} 
12. Timlin MT, Pereira MA, Story M, Neumark-Sztainer D. Breakfast eating and weight change in a 5-year prospective analysis of adolescents: Project EAT (Eating Among Teens). Pediatrics 2008;121(3):e638-45.

13. Gleason PM, Dodd AH. School breakfast program but not school lunch program participation is associated with lower body mass index. J Am Diet Assoc 2009; 109(2,Suppl):S118-28.

14. Must A, Tybor DJ. Physical activity and sedentary behavior: a review of longitudinal studies of weight and adiposity in youth. Int J Obes (Lond) 2005;29(Suppl 2):S84-96.

15. Wong SL, Leatherdale ST. Association between sedentary behavior, physical activity, and obesity: inactivity among active kids. Prev Chronic Dis 2009;6(1):A26 http:// www.cdc.gov/pcd/issues/2009/jan/07_0242.htm.

16. Steffen LM, Dai S, Fulton JE, Labarthe DR. Overweight in children and adolescents associated with TV viewing and parental weight: Project HeartBeat! Am J Prev Med 2009; 37(1,Suppl):S50-5.

17. Drake KM, Beach ML, Longacre MR, MacKenzie T, Titus LJ, Rundle AG, et al. Influence of sports, physical education, and active commuting to school on adolescent weight status. Pediatrics 2012;130(2):e296-304.

18. Videon TM, Manning C. Influences on adolescent eating patterns: the importance of family meals. J Adolesc Health 2003;32(5):365-73.

19. He M, Piche L, Beynon C, Harris S. Screen-related sedentary behaviors: children's and parents' attitudes, motivations, and practices. J Nutr Educ Behav 2010;42(1):17-25.

20. Gubbels JS, Kremers SPJ, Stafleu A, de Vries SI, Goldbohm RA, Dagnelie PC, et al. Association between parenting practices and children's dietary intake, activity behavior and development of body mass index: the Koala Birth Cohort Study. Int J Behav Nutr Phys Act 2011;8:18-31.

21. Sleddens EF, Gerards SM, Thijs C, de Vries NK, Kremers SP. General parenting, childhood overweight and obesityinducing behaviors: a review. Int J Pediatr Obes 2011;6(2-2):e12-27.

22. Kant AK, Miner P. Physician advice about being overweight: association with self-reported weight loss, dietary, and physical activity behaviors of US adolescents in the National Health and Nutrition Examination Survey, 1999-2002. Pediatrics 2007; 119(1):e142-7.

23. Delva J, Johnston LD, O'Malley PM. The epidemiology of overweight and related lifestyle behaviors: racial/ethnic and socioeconomic status differences among American youth. Am J Prev Med 2007;33(4,Suppl):S178-86.
24. Janssen I, Katzmarzyk PT, Boyce WF, King MA, Pickett W. Overweight and obesity in Canadian adolescents and their associations with dietary habits and physical activity patterns. J Adolesc Health 2004;35(5):360-7.

25. Huh J, Riggs NR, SpruijtMetz D, Chou C, Huang Z, Pentz M. Identifying patterns of eating and physical activity in children: a latent class analysis of obesity risk. Obesity (Silver Spring) 2011;19(3):652-8.

26. Centers for Disease Control and Prevention. Youth Risk Behavior Surveillance Questionnaire. http://www.cdc.gov/ healthyyouth/yrbs/questionnaire_rationale.htm. Accessed April 2, 2014.

27. Brener ND, Kann L, McManus T, Kinchen SA, Sundberg EC, Ross JG. Reliability of the 1999 Youth Risk Behavior Survey Questionnaire. J Adolesc Health 2002;31(4):336-42.

28. Lanza ST, Flaherty BP, Collins LM. Latent class and latent transition analysis. In: Schinka JA, Velicer WE, editors. Handbook of psychology: research methods in psychology. New York (NY): Wiley; 2003. p. 663-685.

29. Lanza ST, Collins LM, Schafer JL, Flaherty BP. Using data augmentation to obtain standard errors and conduct hypothesis tests in latent class and latent transition analysis. Psychol Methods 2005;10(1):84-100.

30. Huang TT, Borowski LA, Liu B, Galuska DA, BallardBarbash R, Yanovski SZ, et al. Pediatricians' and family physicians' weight-related care of children in the US. Am J Prev Med 2011;41(1):24-32.

\footnotetext{
The opinions expressed by authors contributing to this journal do not necessarily reflect the opinions of the U.S. Department of Health and Human Services, the Public Health Service, the Centers for Disease Control and Prevention, or the authors' affiliated institutions.
} 


\section{Tables}

Table 1. Demographic and Behavioral Characteristics of Surveyed Youths, Total Sample and by Group, Nebraska, 2008

\begin{tabular}{|c|c|c|c|c|}
\hline Variables & $\begin{array}{l}\text { Total Sample } \\
(n=791), \%\end{array}$ & $\begin{array}{l}\text { Group I }(n= \\
410), \%\end{array}$ & $\begin{array}{l}\text { Group II }(n= \\
237), \%\end{array}$ & $\begin{array}{l}\text { Group III }(n= \\
144), \%\end{array}$ \\
\hline Percentage of total sample & 100 & 52 & 30 & 18 \\
\hline \multicolumn{5}{|l|}{ Age, y } \\
\hline $12-14$ & 46 & $56^{\mathrm{b}, \mathrm{c}}$ & $36^{\mathrm{a}}$ & $35^{\mathrm{a}}$ \\
\hline \multicolumn{5}{|l|}{ Sex } \\
\hline Male & 53 & $57^{c}$ & 53 & $41^{a}$ \\
\hline \multicolumn{5}{|l|}{ Race/ethnicity } \\
\hline Non-Hispanic white & 85 & $89^{c}$ & 85 & $76^{a}$ \\
\hline \multicolumn{5}{|l|}{ Parents' education } \\
\hline Neither parent went to college & 12 & $9^{c}$ & 12 & $19^{a}$ \\
\hline \multicolumn{5}{|l|}{ Family structure } \\
\hline Lives with both parents & 87 & $91^{\mathrm{b}, \mathrm{c}}$ & $82^{a}$ & $83^{a}$ \\
\hline \multicolumn{5}{|l|}{ Dietary behaviors } \\
\hline Eats breakfast every day & 61 & $76^{\mathrm{b}, \mathrm{c}}$ & $55^{a, c}$ & $25^{\mathrm{a}, \mathrm{b}}$ \\
\hline $\begin{array}{l}\text { Eats } 5 \text { servings of fruits and vegetables a day for } 4 \text { days or } \\
\text { more per week }\end{array}$ & 63 & $75^{\mathrm{b}, \mathrm{c}}$ & $55^{a}$ & $44^{a}$ \\
\hline \multicolumn{5}{|l|}{ Physical activities } \\
\hline Has 60 min of physical activity on 4 days or more per week & 80 & $92^{\mathrm{b}, \mathrm{c}}$ & $80^{\mathrm{a}, \mathrm{c}}$ & $47^{\mathrm{a}, \mathrm{b}}$ \\
\hline Participates on at least 1 sports team & 77 & $93^{\mathrm{b}, \mathrm{c}}$ & $73^{\mathrm{a}, \mathrm{c}}$ & $37^{\mathrm{a}, \mathrm{b}}$ \\
\hline $\begin{array}{l}\text { Watches TV or plays video games less than } 2 \mathrm{~h} \text { per day on } \\
\text { weekdays }\end{array}$ & 67 & $78^{\mathrm{b}, \mathrm{c}}$ & $65^{\mathrm{a}, \mathrm{c}}$ & $39^{a, b}$ \\
\hline \multicolumn{5}{|l|}{ Parenting practices } \\
\hline Parents let youth choose what to eat & 80 & $75^{c}$ & $81^{c}$ & $94^{a, b}$ \\
\hline $\begin{array}{l}\text { Parents let youth decide how much to watch TV or play } \\
\text { video games }\end{array}$ & 66 & $61^{c}$ & $62^{c}$ & $88^{\mathrm{a}, \mathrm{b}}$ \\
\hline \multicolumn{5}{|l|}{ Physician advice } \\
\hline $\begin{array}{l}\text { Physician mentioned nutrition during last routine physical } \\
\text { exam }\end{array}$ & 57 & $86^{\mathrm{b}, \mathrm{c}}$ & $\mathrm{O}^{\mathrm{a}, \mathrm{c}}$ & $67^{\mathrm{a}, \mathrm{b}}$ \\
\hline $\begin{array}{l}\text { Physician mentioned physical activity during last routine } \\
\text { physical exam }\end{array}$ & 61 & $88^{b}$ & $0^{a, c}$ & $85^{b}$ \\
\hline \multicolumn{5}{|l|}{ Overweight status } \\
\hline $\mathrm{BMI}\left(\mathrm{kg} / \mathrm{m}^{2}\right)$ equal to or greater than 85 th percentile & 24 & $21^{\mathrm{c}}$ & $20^{c}$ & $41^{a, b}$ \\
\hline
\end{tabular}

Abbreviations: BMI, body mass index.

a Indicates the number is significantly different from that of Group I at the $P=.05$ level.

${ }^{\mathrm{b}}$ Indicates the number is significantly different from that of Group II at the $P=.05$ level.

${ }^{\mathrm{C}}$ Indicates the number is significantly different from that of Group III at the $P=.05$ level.

The opinions expressed by authors contributing to this journal do not necessarily reflect the opinions of the U.S. Department of Health and Human Services, the Public Health Service, the Centers for Disease Control and Prevention, or the authors' affiliated institutions. 
Table 2. Latent Classes of Adolescents Based on Dietary Behavior, Physical Activity, Parenting Practices, and Physician Advice ( $\mathrm{N}=$ 791) ${ }^{\mathrm{a}}$, Nebraska, 2008

\begin{tabular}{|c|c|c|c|}
\hline & Group I & Group II & Group III \\
\hline Response Probability & $\begin{array}{c}\text { Healthy Dietary Behavior } \\
\text { and Physical Activity, Less } \\
\text { Permissive Parenting, and } \\
\text { Physician Advice }\end{array}$ & $\begin{array}{c}\text { Moderately Healthy Dietary } \\
\text { Behavior and Physical Activity, } \\
\text { Less Permissive Parenting, No } \\
\text { Physician Advice }\end{array}$ & $\begin{array}{c}\text { Unhealthy Dietary Behavior } \\
\text { and Physical Activity, More } \\
\text { Permissive Parenting, and } \\
\text { Physician Advice }\end{array}$ \\
\hline \multicolumn{4}{|l|}{ Dietary behaviors } \\
\hline Eats breakfast every day & 0.76 & 0.55 & 0.32 \\
\hline $\begin{array}{l}\text { Eats } 5 \text { servings of fruits and } \\
\text { vegetables on } 4 \text { or more days a } \\
\text { week }\end{array}$ & 0.76 & 0.54 & 0.45 \\
\hline \multicolumn{4}{|l|}{ Physical activities } \\
\hline $\begin{array}{l}\text { Has } 60 \text { min of physical activity on } 4 \\
\text { or more days a week }\end{array}$ & 0.90 & 0.80 & 0.56 \\
\hline $\begin{array}{l}\text { Participates on at least } 1 \text { sports } \\
\text { team }\end{array}$ & 0.92 & 0.73 & 0.47 \\
\hline $\begin{array}{l}\text { Watches television or plays video } \\
\text { games less than } 2 \mathrm{~h} \text { per day during } \\
\text { weekdays }\end{array}$ & 0.78 & 0.63 & 0.42 \\
\hline \multicolumn{4}{|l|}{ Parenting practices } \\
\hline $\begin{array}{l}\text { Parents let youth choose what to } \\
\text { eat }\end{array}$ & 0.74 & 0.81 & 0.93 \\
\hline $\begin{array}{l}\text { Parents let youth decide how much } \\
\text { to watch television or play video } \\
\text { games }\end{array}$ & 0.60 & 0.62 & 0.86 \\
\hline \multicolumn{4}{|l|}{ Physician advice } \\
\hline $\begin{array}{l}\text { Physician mentioned nutrition at } \\
\text { last routine physical exam }\end{array}$ & 0.84 & 0.01 & 0.67 \\
\hline $\begin{array}{l}\text { Physician mentioned exercise or } \\
\text { physical activity at last routine } \\
\text { physical exam }\end{array}$ & 0.86 & 0.04 & 0.79 \\
\hline
\end{tabular}

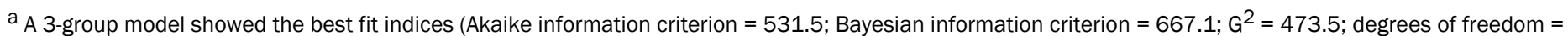
482).

The opinions expressed by authors contributing to this journal do not necessarily reflect the opinions of the U.S. Department of Health and Human Services, the Public Health Service, the Centers for Disease Control and Prevention, or the authors' affiliated institutions. 
Table 3. Logistic Regression Results of Predicting Youth Overweight Status by Youth Groups after Controlling for Demographic Variables ( $=791)$, Nebraska, 2008

\begin{tabular}{|c|c|c|}
\hline Explanatory Variables & Odds Ratio $(95 \% \mathrm{Cl})$ & $P$ Value \\
\hline Group I & $0.44(0.26-0.75)$ & .002 \\
\hline Group II & $0.35(0.25-0.48)$ & $<.001$ \\
\hline Group III & & 1 [Reference] \\
\hline Aged $12-14$ y & $1.21(0.89-1.67)$ & 0.23 \\
\hline Aged $15-19$ y & & 1 [Reference] \\
\hline Male & $1.50(1.42-1.59)$ & $<.001$ \\
\hline Female & & 1 [Reference] \\
\hline Non-Hispanic white & $0.31(0.22-0.46)$ & $<.001$ \\
\hline Minority race ${ }^{a}$ & & 1 [Reference] \\
\hline Neither parent attended college or university & $1.12(0.84-1.49)$ & 0.44 \\
\hline Either parent attended college or university (reference group) & & 1 [Reference] \\
\hline Lives with both parents & $0.87(0.56-1.32)$ & 0.51 \\
\hline Does not live with both parents & & 1 [Reference] \\
\hline
\end{tabular}

Abbreviation: $\mathrm{Cl}$, confidence interval.

a Includes all youths who did not identify themselves as non-Hispanic white. 